
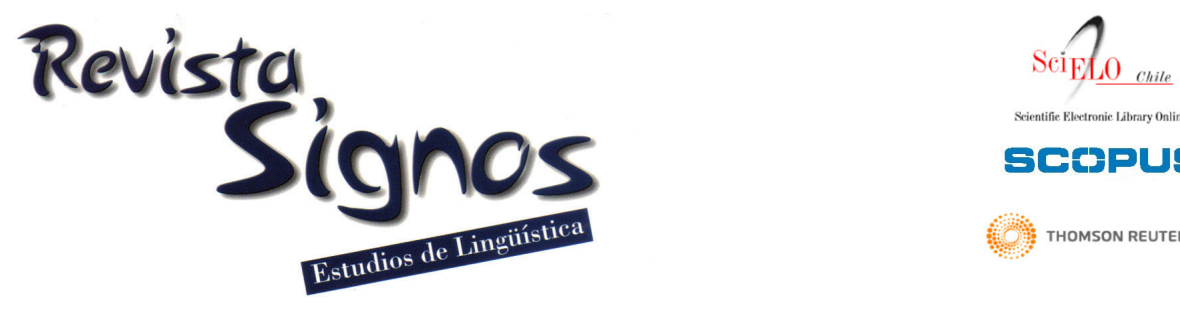

\title{
La ausencia de marcación de caso en los objetos directos con referente humano en posición inicial
}

\author{
The absence of case marking of the direct object with human \\ reference in initial position
}

\author{
Blanca Sanz \\ blancasanz27@hotmail.com \\ Universidad Autónoma de Aguascalientes \\ México
}

Recibido: 9-III-2010 / Aceptado: I8-I-20II

Resumen: El objeto directo con referente humano individualizado suele marcarse con la preposición 'a'. No obstante, cuando el objeto directo se encuentra en posición inicial de oración, suele perder la marca de caso, aun cuando el referente sea humano e individualizado, como en el siguiente ejemplo, donde el objeto directo se disloca a la izquierda: 'ella la recomendó un cuñado mío'. El propósito del artículo consiste en determinar los factores sintácticos que intervienen en la desmarcación de caso. La metodología de este trabajo se basa en la obtención de datos de cuatro corpora del español oral mexicano. Los resultados de la investigación señalan que los objetos directos con referente humano carentes de marca presentan ciertos rasgos propios del sujeto oracional, en tanto que se apegan más a las jerarquías de topicalidad e individuación.

Palabras Clave: Marcación diferencial de objeto, dislocación a la izquierda, jerarquías de individuación y animacidad. 


\begin{abstract}
The direct object with human reference is marked with the preposition $a$. However, when the direct object is located in initial position it usually tends to lose the case mark, even though the referent is human and individual, as it is illustrated in the following example: ella la recomendó un cuñado mío. The aim of this article is to determine the syntactic factors involved in the absence of case marking. The methodology of this work is based on the data from four corpora of the Spanish spoken in Mexico. The results of the investigation show that direct objects with human reference without the presence of case mark have certain subject sentence features given their proximity to the topicality and individuation hierarchies.
\end{abstract}

Key Words: Differential object marking, left dislocation, topicality and individuation hierarchies.

\section{INTRODUCCIÓN}

Muchas lenguas del mundo, incluido el español, presentan el fenómeno conocido como Marcación Diferencial de Objeto (Differential Object Marking), el cual se refiere a que no existe una relación uno a uno entre la marca de caso y la función sintáctica, a diferencia de lo que sucede, por ejemplo, en latín, donde todos los complementos directos reciben un sufijo de acusativo, o en inglés, cuyos complementos directos nunca se marcan. Así, en las lenguas que presentan Marcación Diferencial de Objeto, no todos los complementos directos reciben una misma marca, sino que son divididos en grupos diferentes de acuerdo con sus rasgos semánticos y pragmáticos. Generalmente, solo un grupo recibe una marca, mientras que el otro grupo queda sin marcar (Aissen, 2003).

La marcación diferencial del objeto del español corresponde a la alternancia entre ausencia y presencia de la preposición 'a' en el objeto directo. Como es sabido, en general, los elementos afectados por la acción transitiva de un verbo deben aparecer con marca si son humanos, suprahumanos (Dios, los ángeles, el Diablo, etc.) o cosas personificadas (R.A.E., 2009). Sin embargo, el rasgo [+humano] no es el único factor que regula la aparición de 'a'.

La explicación más generalizada con respecto a la marcación diferencial es que el objeto directo con referente humano, de ahora en adelante OD [+hum], se marca siempre que sea determinado, lo cual explicaría la ausencia y presencia de 'a' en el siguiente par mínimo:

(la) Busco un abogado.

(Ib) Busco a un abogado.

La oración (Ib) es formalmente marcada respecto a la primera. La diferencia semántica estriba en que
(Ib) sugiere a un abogado específico, mientras que (la) se refiere a cualquier abogado.

Si bien la marcación del OD [+hum] presenta alternancias, existe un dominio de obligatoriedad de la presencia de 'a', a saber: la serie tónica de los pronombres personales, los nombres propios de personas y de animales y los pronombres demostrativos e interrogativos cuando se refieren a seres humanos (Laca, 1995; R.A.E., 2009). No obstante, cuando el OD [+hum] se encuentra en posición inicial, este ámbito de obligatoriedad no siempre se cumple, como se observa en el siguiente ejemplo del corpus del Habla popular de la República Mexicana, donde el objeto directo es un pronombre personal $y$, pese a ello, aparece desmarcado:

(2) Pues... nosotros nos perseguían.

Diversos ejemplos de este tipo, documentados en la lengua oral, nos llevan a pensar que la posición del objeto directo motiva la ausencia de la marca. Así, los objetivos de este trabajo se centran en analizar los factores semántico-pragmáticos involucrados en la demarcación del OD [+hum] individuado.

Mediante un análisis contrastivo, demostraremos que las condiciones de marcación diferencial de los objetos directos en posición inicial son distintas a las de los objetos directos en posición postverbal.

En primer lugar,observaremos que existen dos clases de objetos directos en posición inicial: aquellos que presentan un pronombre correferencial (dislocados a la izquierda) y aquellos que carecen de este (topicalizados).

Asimismo, analizaremos los rasgos referenciales vinculados con la identificabilidad e individuación de 
Tabla I. Escala de individuación.

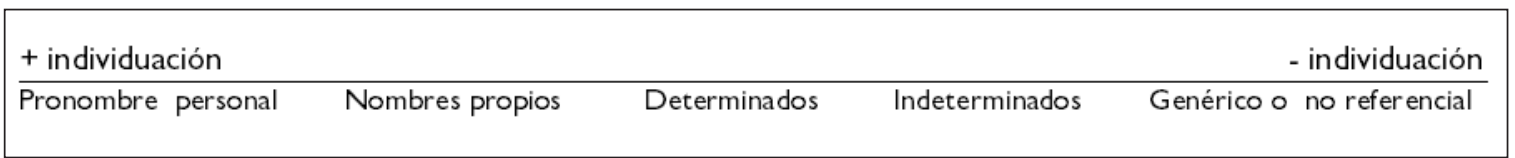

los ODs [+hum], lo cual nos permitirá demostrar que aquellos que se encuentran dislocados se aproximan en mayor medida a los puntos más altos de las jerarquías tipológicas de individuación.

Por otro lado, mostraremos que los ODs [+hum] carentes de marca se encuentran dislocados a la izquierda. Argumentaremos que, en tales casos, no existe una correspondencia sintáctica entre el objeto directo y el pronombre duplicado.

A lo largo del artículo, se podrá observar que los ODs [+hum] en posición inicial comparten una serie de rasgos pragmáticos con el sujeto oracional; pero además señalaremos que los objetos directos carentes de marca no solo comparten características pragmáticas con el sujeto, sino también sintácticas, en tanto que carecen de una marca de caso.

Por último, demostraremos que, al contrario de lo que sucede con los ODs [+hum] en posición postverbal, aquellos que se encuentran en posición inicial tienden a perder la marca de caso cuando son altamente individuados.

\section{Metodología}

Los datos de la investigación provienen de cuatro corpora de lengua oral: el Habla Popular de la República Mexicana (H.P.R.M.)', el Habla Popular de la Ciudad de México (H.P.C.M.) ${ }^{2}$, el Habla de la Ciudad de México (H.C.M.) ${ }^{3}$ y el Habla Universitaria (H.U.) ${ }^{4}$.

El proceso que se siguió para la obtención de datos consistió en buscar todas las frases nominales de objeto directo con referente humano en los cuatro corpora, excepto los objetos del verbo 'haber' y'tener', pues el primero nunca se rige con la preposición 'a' y el segundo, muy rara vez ${ }^{5}$ (Leonnetti, 2003); por lo tanto, tales acusativos no resultan pertinentes para este análisis, ya que el aspecto abordado en el trabajo es la alternancia entre la presencia y ausencia de la preposición 'a'. Posteriormente, se clasificaron los objetos directos con referente humano en dos grandes grupos: I) con preposición (628 ejemplos) y 2) sin preposición (2I5 ejemplos).

Ahora bien, cada uno de los dos grupos anteriores con preposición y sin preposición- se subdividió en dos categorías. En la primera categoría se inscriben los objetos directos que conforman nuestro objeto de estudio: aquellos que se encuentran en posición inicial de frase. De esta categoría, se obtuvieron 64 ejemplos, de los cuales 20 carecen de 'a' (31,25\%). La segunda categoría corresponde al resto de los objetos directos, es decir, aquellos que se encuentran en posición postverbal; estos suman un total de 783 casos, de los cuales 195 carecen de 'a' (24,9\%). Tal categoría permitió hacer un análisis contrastivo entre los objetos en posición inicial y los postverbales.

Puesto que la determinación es un rasgo sumamente relevante para entender la variación en el uso preposicional del OD [+hum], cada categoría se clasificó de acuerdo con el siguiente continuum de individuación como señala la Tabla I.

Los pronombres personales ocupan la posición más alta en la escala de determinación, debido a su carácter personal e individualizante. Después vienen los nombres propios, los cuales son altamente determinados, pues a través de la referencia indicada se da una identificación específica de una entidad en la mente del hablante. Posteriormente, aparecen los determinados y luego los indeterminados. Por último, aparecen los genéricos o no referenciales. Esta escala de individuación será abordada con mayor detalle a lo largo del trabajo.

\section{Alteración del orden básico de la oración}

Diversos estudios de tipología lingüística han demostrado que la distribución de las palabras y sintagmas no se hace del mismo modo en todas las lenguas del mundo. Así, el orden de los constituyentes de la oración es uno de los parámetros tipológicos fundamentales. De acuerdo con Greenberg (1963), 
la disposición de los constituyentes se basa en el orden de tres elementos: sujeto, verbo y objeto, de manera que las posibilidades combinatorias son las siguientes:

\section{(3) a.SVO b. SOV c.VSO \\ d.VOS e.OVS f.OSV}

Al ser el español una lengua de orden básico SVO, las oraciones con objeto directo en posición inicial son muy marcadas. Los datos obtenidos del corpus confirman lo anterior, pues de los 843 objetos directos con referente humano, únicamente 64 $(7,5 \%)$ aparecen en dicha posición.

La alteración del orden de palabras constituye un mecanismo para destacar un determinado elemento del enunciado y para recuperar información precedente del contexto (Padilla, 2005). Para lograrlo, el hablante dispone de dos mecanismos: la topicalización y la dislocación. En función de lo anterior, algunos lingüistas hablan de un único fenómeno y solamente utilizan el término topicalización (Padilla, 2005). Sin embargo, ambos fenómenos presentan características sintácticas distintivas.

Tanto la topicalización como la dislocación colocan a un elemento de la oración en una posición pragmáticamente relevante. La diferencia entre dislocación y topicalización radica en la presencia o ausencia de un clítico correferencial como marca de cambio de posición. En caso de que esta aparezca, tenemos una dislocación; en caso contrario, una topicalización (Padilla, 2005). Los siguientes ejemplos (Padilla, 2005: 25) ilustran el contraste entre ambos tipos de construcciones:

(4a) Topicalización:Tortillas no llegué a hacer.

(4b) Dislocación: La casa la compré yo.

Otra diferencia entre topicalización y dislocación radica en lo siguiente: se pueden topicalizar distintas funciones sintácticas, pero las dislocaciones afectan siempre y únicamente a los objetos (especialmente al directo) (Padilla, 2005).

El elemento dislocado se puede situar a la izquierda - a la derecha. Cuando existe dislocación a la izquierda, el objeto directo o indirecto se sitúa a la izquierda del verbo y a continuación aparece el pronombre correferencial, como se ejemplifica en (5a). Por otra parte, en la dislocación derecha, el objeto directo o indirecto se sitúa a la derecha, es decir, en la parte que le corresponde según el orden no marcado SVO, pero aparece anticipado por un pronombre átono (Pérez, 1998: 256), como se observa en $(5 b)$ :

(5a) El libro, lo compré yo.

(5b) No lo compré, el libro.

En lo que respecta a los datos provenientes del corpus de la presente investigación, los ODs [+hum] en posición inicial pueden estar topicalizados, como en (6a), o dislocados a la izquierda, como en (6b):

(6a) Casi a 'nadien' conozco (H.P.C.M.).

(6b) A su hija la fuimos a buscar a España (H.C.M.).

No obstante, la mayoría de los ODs [+hum], el 93,7\% (60 de 64 oraciones), se encuentran dislocados a la izquierda, en tanto que el objeto se duplica mediante un pronombre correferencial.

A lo largo del trabajo analizaremos las diferencias y semejanzas entre los ODs [+hum] topicalizados y los dislocados.

\section{El valor topical de los objetos en posición inicial}

Los enunciados se organizan en torno a la llamada 'estructura informativa', la cual se encuentra relacionada con las categorías pragmáticas 'tópico' y 'foco'. El tópico de una oración puede definirse como el referente o tema del que trata el resto de la oración (Lambrecht, 1994). El foco, también denominado comentario, se define como la parte de la proposición que no se puede dar por sentada en el momento de la enunciación, es decir, es el elemento imprevisible o no recuperable pragmáticamente en el enunciado (Lambrecht, 1994, van Dijk, 1998)6.

Las oraciones que conforman nuestro objeto de estudio presentan la peculiaridad de que el objeto directo funciona como tópico, pues es el punto de partida para el resto de la oración. Por ejemplo, el asunto de la enunciación de (7), que coincide precisamente con el objeto directo, versa sobre una mujer llamada Yudinca:

\section{(7) A Yudinca la vi hace como un año (H.U.).}

La diferencia entre tópico y comentario también se vincula con el estatus informativo de los elementos de la oración. Mientras que en el tópico se encuentra la información nueva, en el foco, la información conocida. 
De acuerdo con Chafe (1976, 1987), Prince (198I) y Lambrecht (1994), la información puede ser nueva o conocida en función de cuán identificable sea el referente. Según el modelo de identificabilidad, la diferencia entre información nueva y conocida descansa sobre un factor cognoscitivo. El hablante, durante la codificación de su mensaje, realiza presuposiciones acerca del estado de activación en la mente de su oyente. De esta manera, la información dada o conocida puede definirse como el conocimiento que el hablante asume que está en la mente del oyente en el momento de la producción de la cláusula. La información nueva, en contraste, es lo que el hablante asume que está introduciendo en la conciencia del oyente con lo que dice.

Según este modelo, el término 'información dada (o vieja)' no se refiere al conocimiento que el oyente ya posee, por ejemplo, con base en las experiencias que comparten las personas muy relacionadas. Por otro lado, la información nueva tampoco debe entenderse como algo de lo que el oyente todavía no tiene conocimiento. Chafe (1976) explica con claridad lo que hay que entender bajo el término 'información dada' al poner énfasis en la noción 'conciencia' y no 'conocimiento'.

A diferencia de la información nueva, la información conocida no requiere que el oyente produzca una representación de la realidad, pues tal representación de la realidad ya existe en su 'archivo' referencial, ora porque la información existe en la conciencia del oyente, ora porque es inferible o recuperable del contexto lingüístico o la situación (Chafe, 1976; Lambrecht, 1994).

Como habíamos mencionado, los tópicos son portadores de información conocida, lo cual quiere decir que sus referentes son identificables. Veamos el siguiente ejemplo:

(8) A mis amigos de primer semestre los conservo (H.U.).

El posesivo se encarga de dotar al objeto directo de una referencia deíctica, pues vincula el referente del objeto directo con la individualidad del emisor. Así, el oyente puede identificar perfectamente el referente 'amigos', pues el determinante 'mis' indica que los amigos son atribuidos al hablante.

Además del estatus informativo, los tópicos se definen en función de su posición dentro de la oración. Recordemos que, como mencionamos anteriormente, el objeto directo en posición inicial, tanto en la topicalización (sin pronombre correferencial) como en la dislocación (con pronombre correferencial), ocupa una posición pragmáticamente relevante. Givón (1976) señala que cualquier elemento puede aparecer como tópico sea cual sea su función en la frase. Sin embargo, no todos los elementos se emplean como tópicos con la misma frecuencia, pues existe la siguiente jerarquía:

\section{AGENTE > DATIVO > ACUSATIVO}

Las mayúsculas indican que se trata de casos abstractos fillmorianos, no de su manifestación gramatical. De hecho, Duranti y Ochs (1979), al abordar la jerarquía propuesta por Givón (1976), mencionan lo siguiente: "These labels must be interpreted as 'deep or abstract' (Fillmorian) kinds of cases” (Duranti \& Ochs, 1979: 389).

Según dicha jerarquía, el elemento que aparecerá como tópico será preferentemente el sujeto, luego el complemento indirecto $(\mathrm{Cl})$ y en tercer lugar el complemento directo (CD). Ahora bien, en las lenguas con predominio de sujeto (subject prominent), en oposición a aquellas con predominio de tópico, el sujeto reúne muchas de las propiedades que caracterizan a los tópicos; esto es, el sujeto es un tópico gramaticalizado (Li \& Thompson, 1977; Pensado, 1995a). Así, al ocupar la posición que normalmente corresponde a un sujeto (posición inicial), el objeto desempeña la función de tópico. En pocas palabras, la posición más frecuente de los tópicos es la de inicial de frase, debido a las características que comparten con el sujeto ${ }^{7}$.

Como habíamos mencionado, el $93,7 \%$ de los ejemplos del corpus presentan dislocación a la izquierda, y el resto, topicalización. El hecho de que los ODs [+hum] en posición inicial sean en su mayoría dislocaciones se encuentran relacionados con la determinación y especificidad del referente. Si bien los ODs [+hum] en posición inicial se caracterizan por su estatus informativo identificable, podemos reconocer diferentes grados de determinación.

Las construcciones con dislocación a la izquierda tienen como objeto directo un pronombre personal, un nombre propio o una frase nominal con referente definido o genérico, como a continuación se ilustra a partir de los siguientes ejemplos: 
(9a)A 'ella' sí la quise bastante (pronombre personal) (H.P.C.M.).

(9b) A 'Fabiola' me la encontré el otro día (nombre propio) (H.U.).

(9c) Yo 'a estas señoras' las conozco de muchos años (definido) (H.P.C.M.).

(9d) Pero 'a una mujer que trabaja'... jamás... la verás neurasténica (genérico) (H.C.M.).

Los pronombres personales ocupan la posición más alta en la escala de individuación, debido a su carácter personal e individualizante. Después vienen los nombres propios, los cuales son altamente individuados, pues a través de la referencia indicada se da una identificación específica de una entidad en la mente del hablante y el oyente.

Los referentes definidos son más individuados que los indefinidos, pues estos últimos, a diferencia de los primeros, son identificables tanto para el hablante como para el oyente (Chafe, 1976).

Los referentes genéricos, si bien no se refieren a un individuo específico, son identificables, pues se refieren a una clase de individuos de la misma especie (Rodríguez, 2005), como en (9d), donde el objeto directo hace referencia a la clase de mujeres que trabajan.

Los ejemplos de topicalización se caracterizan por tener como objeto directo un cuantificador existencia pronominal de referente humano ('alguien' y 'nadie'), los cuales, si bien pertenecen al grupo de los pronombres indefinidos, en cierta medida son identificables, pues se refieren a un conjunto de seres humanos (R.A.E., 2009: I4571458). Veamos los siguientes ejemplos:

(I0a) Fíjate: yo de aquí casi a 'nadien' conozco... iy yo tantos años que tengo aquí viviendo! (H.P.C.M.). (IOb) Me he encontrado a varios de la prepa. El otro día, por ejemplo, me encontré a... ¿quién era?, jay, no sé! 'A alguien' me encontré, pero no me acuerdo a quién (H.U.).

En el ejemplo ( $\mathrm{IOa}$ ), el oyente, a partir del pronombre indefinido 'nadie', puede identificar un conjunto vacío de gente. Por otro lado, el pronombre 'alguien' del ejemplo (IOb) se refiere a un miembro de un conjunto de personas. Si bien el miembro de este conjunto no es específico, el oyente es capaz de identificar al conjunto en su totalidad: los compañeros de la preparatoria.
En suma, los referentes humanos de los objetos directos de la topicalización, aunque sí son identificables, son menos específicos que aquellos que aparecen dislocados a la izquierda. Entonces, el ser identificable es una condición para que el objeto directo aparezca en posición inicial, pero en el caso de la dislocación izquierda, se requiere además que el referente sea específico.

En la Tabla 2 se pormenorizan los datos cuantitativos vinculados con las diferencias entre dislocación izquierda y topicalización en lo que respecta a los rasgos referenciales del objeto directo.

Tabla 2. Tipo de construcción de OD [+hum] en posición inicial y clase de referente.

\begin{tabular}{|l|c|c|c|}
\cline { 2 - 4 } \multicolumn{1}{c|}{} & DI & TOP & $\%$ DI \\
\hline Pronombres personales & 15 & 0 & 100 \\
\hline Nombres propios & 9 & 0 & 100 \\
\hline Definido & 32 & 0 & 100 \\
\hline Genérico & 4 & 0 & 100 \\
\hline Indefinido & 0 & 4 & 0 \\
\hline
\end{tabular}

Las cifras anteriores pueden explicarse mediante la teoría de Givón (1976). Dicho autor afirma que una restricción universal para las dislocaciones, ya sean derechas o izquierdas, es que el tópico sea definido o genérico, pero nunca referencial indefinido.

Así, de acuerdo con los datos del corpus, podemos deducir que las siguientes oraciones son agramaticales:

(I la) *A Juan amo

(I Ib) *A la mujer los hombres maltratan

(I Ic) * A \{alguien / nadie\} lo vi

La agramaticalidad de las dos primeras oraciones radica en que la condición para que un objeto directo definido o genérico ocupe la posición inicial, es que este se encuentre dislocado y por tanto posea un pronombre copia ${ }^{8}$. Por otro lado, (IIc) resulta agramatical porque la condición para que un objeto directo con referente humano se topicalice, es que tenga un referente indeterminado. La imposibilidad de que exista un pronombre copia radica en la naturaleza semántica de los pronombres indefinidos. 'Nadie' denota un conjunto vacío de humanos, por lo que no puede haber un clítico que recupere a una entidad humana de dicho conjunto. Tampoco puede existir un pronombre que recupere a una 
entidad humana del conjunto denotado por 'alguien', porque el miembro de ese conjunto es inespecífico. Entonces, en ninguno de los dos casos puede existir una recurrencia consistente en la sustitución de una unidad por otra que designa a la misma entidad.

Por lo anterior, las dislocaciones izquierdas se apegan mucho más a la jerarquía de topicalidad propuesta por Givón (1976), la cual es resultado de una serie de relaciones jerárquicas binarias:

humano $>$ no humano

definido $>$ indefinido

participante más implicado $>$ menos implicado

$\mathrm{I}^{\mathrm{a}}$ persona $>2^{\mathrm{a}}$ persona $>3^{\mathrm{a}}$ persona

Según Givón (1976), dicha jerarquía refleja una tendencia en los humanos a hablar más de humanos que de no humanos, lo que es señal de una egoantropocéntrica naturaleza del discurso.

Como ya habíamos mencionado, en español los sujetos son tópicos gramaticalizados, es decir, son los tópicos discursivos por excelencia. Por ello, son los elementos oracionales que más se apegan a la jerarquía antes mencionada. Así, pese a que los objetos topicalizados también se encuentran en posición inicial, los objetos dislocados reúnen más características de sujeto debido a sus características referenciales, es decir, porque tienden a seguir la jerarquía de topicalidad.

\section{Características de los objetos directos con referente humano en posición inicial carentes de marca}

De acuerdo con los datos del corpus, los ODs [+hum] en posición inicial que pierden la marca de caso únicamente son aquellos que se encuentran dislocados (presentan un pronombre que se duplica). En cambio, cuando no existe un pronombre duplicado, la presencia de la marca es obligatoria.

La tercera parte de los objetos dislocados (20 de los 60 ejemplos) carece de marca. Podría pensarse que la variación en el uso de 'a' se debe a que el objeto preposicional en español no se encuentra totalmente gramaticalizado (Pensado, 1995a) ${ }^{9}$. Sin embargo, la marcación con 'a' es obligatoria cuando los objetos directos (postverbales) son pronombres personales o nombres propios, y es muy frecuente cuando los referentes son altamente determinados. Esta condición no se cumple cuando los objetos se encuentran dislocados a la izquierda, como se ha mencionado anteriormente, pues los objetos pueden aparecer con o sin marca. Por ejemplo, en las siguientes oraciones, los objetos directos presentan el mismo grado de individuación, pues son pronombres personales de tercera persona. No obstante, el primero, a diferencia del segundo, aparece sin marca.

( I 2a) $\varnothing$ Ella la recomendó un cuñado mío (H.P.R.M.). (I2b) Y a ella luego me la encuentro (H.U.).

En este caso, lo que licencia la marcación facultativa es la posición del objeto. Para comprobar tal afirmación, observemos que si desplazamos el objeto de (12a) a una posición postverbal, las oraciones resultan agramaticales:

(I 3a) * Recomendó un cuñado mío $\varnothing$ ella.

(I3b) * Un cuñado mío recomendó $\varnothing$ ella.

Los casos en los que el OD aparece sin marca pertenecen a una subclase de dislocación izquierda conocida como no anafórica, que se caracteriza por tener un constituyente dislocado que no es recuperado sintácticamente a través de un pronombre anafórico, de manera que no hay un vínculo sintáctico entre el elemento dislocado y la predicación que le sigue (Hidalgo, 2002). La siguiente oración pertenece a este tipo de construcción:

(14) Yo me parece bien (Marcos Marín, 1992, citado en Hidalgo, 2002).

En esta oración, el experimentante se presenta en forma nominativa, en lugar de manifestarse como una frase preposicional dativa (a mi), de manera que no hay una correspondencia anafórica con el pronombre dativo 'me'.

En lo que respecta a los datos de nuestro corpus, la tercera parte de los objetos directos con referente humano en posición inicial (20/60) carece de 'a'. Sirva como ejemplo la siguiente oración:

(I5) Este... este otro general... jese lo mataron! (H.P.R.M.).

La peculiaridad de esta oración radica en que el paciente no presenta marca de objeto directo, aunque su referente sea humano y determinado, lo cual contraviene las reglas de marcación diferencial de objeto del español. 
Tabla 3. Correspondencia pronominal.

\begin{tabular}{|l|l|l|}
\hline Pronombres nominativos & Pronombres dativos o acusativos \\
\hline Yo & Me & A mí \\
\hline Tú & Te & A ti \\
\hline Él, ella, ello & Se, la, lo, le & A él, a ella, a ello, a sí \\
\hline Nosotros (as) & Nos & A nosotros \\
\hline Vosotros, ustedes & Os, vos & A vosotros, a ustedes \\
\hline Ellos (as) & Se, las, los, les & a ellos (as), a sí \\
\cline { 2 - 2 } & $\uparrow$ & \multicolumn{2}{|c}{$\uparrow$} \\
\cline { 2 - 3 }
\end{tabular}

Todos los objetos directos con referente humano carentes de la marca documentados en el corpus se caracterizan por estar dislocados a la izquierda, esto es, hay un clítico (pronombre acusativo) que se duplica o se copia. En tales casos, no existe una relación anafórica entre el objeto directo y el pronombre, porque no existe una correspondencia sintáctica entre estos elementos, pero sí existe correferencialidad, pues el objeto y el objeto se refieren a la misma entidad.

La dislocación izquierda no anafórica presenta mayor independencia sintáctica que la anafórica por los siguientes motivos. La preposición 'a' es una marca de función sintáctica que se traduce en la oración, pues un dativo o un acusativo se marcan en función del verbo de esta. Por tanto, la marca de caso de alguna manera articula o vincula los elementos de la oración. Así, si se pierde la marca de caso, las relaciones sintácticas se ven interrumpidas. Veamos por qué.

Los pronombres dativos o acusativos átonos tienen su correspondiente pronombre tónico, como se ilustra en la Tabla 3.

Existe una distinción entre pronombres átonos de dativo $\circ$ acusativo (segunda columna) y tónicos (tercera columna, marcados con negritas). Sin embargo, hay pronombres que no tienen una distinción específica de caso: 'nosotros', 'nosotras', 'vosotros', 'vosotras', 'ustedes', 'vos', 'él', 'ella', 'ellos', 'ellas' (R.A.E., 2009). En estos casos, la preposición 'a' se encarga de marcar el caso acusativo o dativo. De esta manera, un pronombre átono puede tener un pronombre correspondiente tónico en función dativo $\circ$ acusativo mediante las formas de los pronombres nominativos más la marca de caso ' $a$ ' (a él, a nosotros, a ellos, etc.), como se muestra en el siguiente ejemplo, donde 'lo' se corresponde con 'a él'.
(I6) A él no lo quieren

En el caso de la tercera persona, el acusativo se puede marcar tanto con un pronombre tónico 'si', como con un pronombre sin distinción específica de caso ('él', 'ella', 'ello', 'ellas', 'ellos'), tal como se ilustra en (I7):

(17a) Él se lastima a sí mismo.

(I 7b) A él no lo quieren.

Ahora bien, aunque existan pronombres tónicos específicos para marcar el acusativo o el dativo, la presencia de 'a' es obligatoria. Así, las construcciones como la ilustrada en (I8) son agramaticales.

(I8) $* \varnothing$ mí no me quieren.

En las dislocaciones izquierdas carentes de preposición, no existe una correspondencia sintáctica entre el tópico y el pronombre correferencial. Observemos los siguientes contrastes:

(I9a) 'A él lo quiero'.

(19b) ‘Él lo quiero’.

En ( 19 a) existe una correspondencia sintáctica entre el objeto directo y el pronombre anafórico, debido a que existe una conformidad de casos entre 'a él' y 'lo': ambos se encuentran en acusativo, pues 'lo' es la forma acusativa de tercera persona de singular y 'a él' marca el caso acusativo mediante la preposición. En (19b), por el contrario, no existe correspondencia sintáctica, pues dado que el pronombre 'él' no marca acusativo mediante la preposición 'a', no presenta conformidad de caso con el pronombre 'lo'.

La conformidad o disconformidad de caso acusativo también puede darse cuando el objeto directo en posición inicial no tiene un pronombre como núcleo de la frase nominal. Compárense las siguientes oraciones: 
(20a) A mi mamá la quiero.

(20b) Mi mamá la quiero.

En (20a), la frase preposicional 'a mi mamá' se encuentra en acusativo debido a la marca de caso 'a', por lo que existe una correspondencia con el pronombre 'la', que también se encuentra en acusativo. En cambio, en (20b), la frase nominal 'mi mamá' no marca acusativo mediante la preposición, mas el pronombre correspondiente a tal frase '(la)' se encuentra en acusativo. En otras palabras, la frase 'mi mamá' se encuentra en nominativo y el pronombre 'la' en acusativo.

De tal suerte, podemos concluir que cuando una dislocación izquierda no posee marca de caso, se disloca como puro tópico, como una especie de declaración tópica inicial, sin marca de caso, por lo que no hay concordancia entre el elemento dislocado y el pronombre que se duplica o se copia. Así, las relaciones sintácticas se ven interrumpidas, de manera que la relación entre tópico y comentario se da en el nivel pragmático y no en el sintáctico.

El objeto directo en posición inicial comparte rasgos pragmáticos con el sujeto, pues, como hemos señalado, presenta el estatus informativo de tópico y está colocado en una posición pragmáticamente relevante.

Ahora bien, el objeto directo no anafórico presenta no solo semejanzas pragmáticas con el sujeto, sino también sintácticas. El español, a falta de morfemas de caso en el nombre, cuenta con todo un sistema de preposiciones que actúan como marcadores de función para los objetos indirectos y, en ocasiones, los directos, los complementos circunstanciales y los complementos del nombre. El objeto directo en posición inicial carente de 'a' es similar al sujeto en la medida en que también carece de una preposición que actúe como marcador.

Lo anterior pone en duda una de las explicaciones tradicionales al fenómeno del complemento directo preposicional, la cual sostiene que cuando el orden relativo del sujeto y el OD no es habitual, aumentaría el uso de la preposición. Según Cuervo (I886), por ejemplo, se trataría fundamentalmente de un recurso para evitar la ambigüedad, pues según él, un $O D$ que encabeza una oración tiende a identificarse con el sujeto. Tal propuesta explica, efectivamente, el hecho de que cuando hay una topicalización del objeto directo con referente humano siempre se marca, dado que existe la necesidad de desambiguarlo mediante la marca de caso 'a'. Sin embargo, en la dislocación izquierda no existe la necesidad de desambiguación, pues el caso es recuperado mediante un pronombre que se duplica o se copia.

En la misma línea se encuentra Pensado (1995a), quien también atribuye la marcación del objeto a la posición. Afirma que el Complemento Directo Preposicional (CDP):

"es especialmente frecuente cuando el CD aparece en posición inicial de frase para dar énfasis (acusativo preposicional de colocación)" (Pensado, 1995a: 204).

El autor señala que su valor primitivo es el siguiente:

A mí, ME OBEDECE

A mí ME OBEDECE

ME OBEDECE a mílo

Más adelante, Pensado (I995a: 204) señala que:

"aunque el CDP haya podido generalizarse a otros contextos y aunque el corte prosódico haya podido desaparecer [...] el valor de tópico del pronombre sigue subsistiendo en las construcciones que hemos postulado como origen del CDP".

La autora considera que en el español actual se prefiere una construcción de marca casual para los $\mathrm{Cl}$ y los $\mathrm{CD}$ animados en posición inicial, a diferencia del francés y del italiano que prefieren un nominativo pendens" , como lo ilustra Pensado (2005a: 209) a partir de los siguientes ejemplos:

(2I) español Cl: 'A Pedro', no 'le' he contado nada CD: 'A Pedro', no 'lo' he visto

francés $\mathrm{Cl}$ : Pierre, je ne lui ai rien raconté CD: Pierre, je ne l'ai pas vu

italiano $\mathrm{Cl}$ : Pietro, non gli ho detto niente CD: Pietro, non l'ho visto

Sin embargo, hemos observado que los ODs [+hum] en posición inicial, dislocados a la izquierda, aparecen frecuentemente sin marca. En estos casos, las construcciones presentan la misma estructura que las del francés e italiano.

Por otro lado, los datos del habla popular muestran que existe una gran tendencia a que la marca de 
Tabla 4. Ausencia y presencia de 'a' en el OD [+hum] en posición inicial.

\begin{tabular}{|l|c|c|c|}
\hline Corpus & Sin 'a' & Con 'a' & \% sin 'a' \\
\hline Habla Popular de la República Mexicana & 10 & 7 & 85,8 \\
\hline Habla Popular de la Ciudad de México & 6 & 9 & 40 \\
\hline Habla de la Ciudad de México & 1 & 12 & 7,6 \\
\hline Habla Universitaria & 3 & 12 & 20 \\
\hline
\end{tabular}

objeto desaparezca, mas no en el habla culta. La Tabla 4 muestra el porcentaje de ODs [+hum] no marcados en dislocaciones izquierdas ${ }^{12}$.

Como se puede advertir, el porcentaje de desmarcación en las hablas populares es mucho más elevado, sobre todo en el Habla Popular de la República Mexicana. Estos datos quizá revelen que la DI sin preposición se da en contextos más conversacionales y espontáneos, pues dicho corpus se compone exclusivamente de conversaciones informales. De hecho, la dislocación izquierda es una construcción estigmatizada. Al respecto, la R.A.E. (2009: 2980) señala lo siguiente:

"Es frecuente en la lengua espontánea de muchos países, así como en las variantes más informales del registro coloquial, la discordancia que se observa en 'Yo, me parece que'... (por 'A mí me parece que'...) Esta construcción está desprestigiada, por lo que se recomienda evitarla en todo tipo de expresiones".

No obstante, independientemente de que la dislocación izquierda no anafórica sea inaceptable desde un punto de vista normativo, responde a una estrategia comunicativa de los hablantes, en tanto que permite vincular el tópico y el comentario, no de una manera sintáctica, pero sí pragmática.

\section{Objetos en posición inicial vs. objetos en posición postverbal}

Diversos autores han señalado que el grado de individualidad del objeto es un factor que determina la presencia de la preposición 'a' en los acusativos. Hopper y Thompson (1975) definen la individuación, que para ellos es un parámetro de transitividad en las distintas lenguas, como el contraste del complemento directo, tanto con su agente como con su propio entorno. Estos autores consideran que la individuación es un compuesto de las siguientes propiedades binarias del nombre:
Propio / común

Humano, animado / inanimado

Definido / no definido

Referencial/ no referencial

Singular/ plural

Numerable / masa

Los referentes nominales con las propiedades de la izquierda se encuentran más individuados que los de la derecha. Así, la preposición 'a' tiende a aparecer con los referentes que manifiestan una o más de las propiedades de la izquierda. De hecho, el origen histórico y la evolución del uso de 'a' se encuentra también determinado por el grado de individuación. Como resultado de la evolución de la marcación de caso de los ODs [+hum], la preposición es obligatoria para los nombres propios y los pronombres personales y, en la mayoría de los casos, aparece cuando el acusativo tiene un referente definido. En cuanto a los acusativos indeterminados, no referenciales o genéricos, estos tienden a carecer de preposición (Pensado, 1995b). En pocas palabras, cuanto más determinado sea el referente del objeto directo, más probabilidades habrá de que aparezca marcado.

Sin embargo, los objetos en posición inicial no siguen este comportamiento. Hemos visto que cuando los objetos se encuentran topicalizados siempre se marcan, pese a tener un referente inespecífico. Por otro lado, los objetos dislocados a la izquierda pueden carecer de marca, aunque presenten un referente altamente determinado, como un pronombre personal o un nombre propio. Lo anterior no es de extrañar si tomamos en cuenta que los objetos dislocados son muy similares a los sujetos, debido a la tendencia antes mencionada de seguir la jerarquía de topicalidad propuesta por Givón (1976). 
Tabla 5. ODs [+hum] dislocados a la izquierda.

\begin{tabular}{|l|c|c|c|}
\cline { 2 - 4 } \multicolumn{1}{c|}{} & Sin ' $a$ ' & Con ' $a$ ' & \% con 'a' \\
\hline Pronombres personales o nombres propios & 6 & 18 & 68,75 \\
\hline Frases nominales con referente determinado & 14 & 18 & 50 \\
\hline Frase nominal con referente indeterminado & 0 & 0 & - \\
\hline Frase nominal no referencial o con referente genérico & 0 & 4 & 100 \\
\hline
\end{tabular}

Tabla 6. ODs [+hum] postverbales.

\begin{tabular}{|l|c|c|c|}
\cline { 2 - 4 } \multicolumn{1}{c|}{} & Sin 'a' & Con ' $a$ ' & \% con ' $a$ ' \\
\hline Pronombres personales o nombres propios & 2 & 1 । 4 & 98,27 \\
\hline Frases nominales con referente determinado & 30 & 231 & 88,50 \\
\hline Frases nominales con referente indeterminado & 76 & 137 & 64,31 \\
\hline Frase nominal no referencial o con referente genérico & 87 & 106 & 54,92 \\
\hline
\end{tabular}

Así pues, la ausencia de 'a' en los objetos directos con referente humano dislocados sigue el comportamiento inverso al de los objetos en posición postverbal. Para comprobar tal afirmación, véanse las Tablas 5 y 6 , las cuales muestran cómo se asocia la determinación del referente del objeto directo con la marcación.

Nótese que en la categoría de los objetos dislocados marcados sí aparecen algunos no referenciales e indeterminados, pero no en los desmarcados. Obsérvese también en la Tabla 6, que a medida que los referentes de los objetos postverbales son menos determinados o referenciales, se tiende a perder la marcación de caso, lo cual se refleja en la disminución del porcentaje en la Tabla $6^{13}$. Todo lo contrario sucede con los objetos dislocados: estos tienden a perder la marcación de caso cuando son determinados.

Una vez expuestas las consideraciones anteriores, podemos concluir lo siguiente: Un OD [+hum] dislocado a la izquierda tiende a perder la marca de caso cuando es más individuado, esto es, cuando posee más características del lado izquierdo de la jerarquía binaria de Hopper y Thompson (1975). Los objetos directos postverbales, por el contrario, tienden a perder la marcación cuando son menos individuados, es decir, cuando poseen más rasgos del lado derecho de la jerarquía binaria antes mencionada.

Lo anterior se debe a que los objetos dislocados, al ocupar la posición de tópico, tienden a adquirir una de las características de los sujetos en español: la no marcación. El hecho de que los ODs adquieran características de sujeto se debe a que estos son los que, como señala Givón (1976), más frecuentemente ocupan la posición de tópico.

En suma, un factor sumamente importante en la ausencia o presencia de la marca de caso en el OD [+hum] es la posición de este dentro de la oración.

\section{CONCLUSIONES}

El español es una lengua de marcación diferencial de objeto, pues el objeto directo con referente humano recibe una marca especial de caso. En la bibliografía sobre el tema, se ha dicho que hay un ámbito de obligatoriedad de 'a' en: la serie tónica de los pronombres personales, los nombres propios de personas y de animales y los pronombres demostrativos e interrogativos cuando se refieren a seres humanos. Sin embargo, en este trabajo señalamos que este ámbito de obligatoriedad no se cumple cuando el objeto directo se encuentra en posición inicial, pues en la lengua oral son frecuentes las expresiones del siguiente tipo: 'Él lo conocí en el trabajo'.

A lo largo del trabajo mostramos que, puesto que el español es una lengua de orden básico SVO, el objeto directo en posición inicial es muy marcado y que dicha alteración del orden supone un mecanismo para colocar al objeto en una posición pragmáticamente relevante. Mencionamos que, para lograrlo, el hablante dispone de dos mecanismos: 
la topicalización y la dislocación izquierda. Ambos fenómenos consisten en colocar un elemento en posición inicial, pero la dislocación se distingue de la topicalización en que la primera únicamente afecta a los objetos (directo e indirecto) y además presenta un clítico correferencial.

A partir del análisis cuantitativo, demostramos que la dislocación izquierda es mucho más frecuente que la topicalización y que, únicamente en el contexto de esta última, el OD [+hum] aparece desmarcado.

Aducimos que la diferencia entre la topicalización y la dislocación descansa en la estructura informativa de la oración, pues una condición necesaria para que el objeto directo aparezca en posición inicial es que sea identificable, pero tratándose de una dislocación izquierda, éste debe ser, además, específico. Así, de acuerdo con la jerarquía de topicalidad propuesta por Givón ( 1976), el OD [+hum] dislocado presenta más características de tópico que el OD [+hum] carente de pronombre correferencial.
Por otro lado, analizamos las construcciones en las que el OD [+hum] en posición inicial carece de 'a'. Estas pertenecen a la clase de la dislocación no anafórica y se caracterizan por presentar una interrupción sintáctica entre el tópico y comentario, de manera que la relación entre estos dos elementos es pragmática. Argumentamos que los objetos directos dislocados a la izquierda presentan semejanzas con el sujeto, debido a que además de ocupar una posición pragmáticamente relevante y ser altamente individuados, también carecen de una preposición que actúe como marcador.

Por último, analizamos las diferencias entre los ODs [+hum] que se encuentran en posición inicial y aquellos que aparecen en posición postverbal. Concluimos que un factor de suma importancia para la ausencia o presencia de 'a' es la ubicación del $\mathrm{OD}$ en la oración. Argumentamos que, al contrario de lo que sucede con los ODs [+hum] en posición postverbal, los que se encuentran dislocados a la izquierda tienden a perder la marca de caso cuando son más individuados. 


\section{REFERENCIAS BIBLIOGRÁFICAS}

Aissen, J. (2003). Differential Object Marking: Iconicity vs. economy. Natural Language \& Linguistic Theory, 2I , 435-483.

Chafe,W. (1976). Givenness, contrastivenes, definiteness, subjects, topics and point of view. En Ch. Li (Ed.), Subject and topic (pp. 25-55). New York:Academic Press.

Chafe, W. (1987). Cognitive contrasts on information flow. En R. Tomlin (Ed.), Coherence and grounding in discourse. Typological studies in language (pp. 21-5I). Amsterdam: Jonh Benjamins.

Cuervo, R.J. ( 1886$)$. Diccionario de construcción y régimen de la lengua castellana. Bogotá: Instituto Caro y Cuervo.

Duranti,A. \& Ochs, E. (1979). Left dislocation in Italian conversation. En T. Givón (Ed.), syntax and semantics 12. Discourse and syntax (pp. 337-416). New York:Academic Press.

Givón, T. (1976). Topic. Pronoun and grammatical agreement. En Ch. Li (Ed.), Subjet and topic. (pp. 149-185). New York:Academic Press.

Greenberg, J. (1963). Universals of language. Cambridge: MIT Press.

Hidalgo, R. (2002). Establishing topic in conversation:A contrastive study of left-dislocation in English and Spanish. En A. Downing, J. Moya \& J. I.Albentosa (Coord.), Circle of linguistics applied to Communication II (pp. 3 I-50). Cuenca:Ediciones de la Universidad de CastillaLa Mancha.

Hopper, P. J. \&.Thompson S.A. (1975). Subject and topic:A new typology of languaje. En Ch. Li (Ed.), Subjet and Topic (pp. I49-185). New York:Academic Press.

Lambrecht, K. (1994). Information structure and sentence form. Topic, focus, and mental representations of discourse referents. Cambridge: Cambridge University Press.

Laca, B. (1995). Sobre el uso del acusativo preposicional en español. En C. Pensado (Ed.), El complemento directo preposicional (pp. 6I-9I). Madrid:Visor Libros.

Leonetti, M. (2003). Specificity and object marking: The case of Spanish a. Ponencia presentada en el Congreso Semantic and Syntactic Aspects of Specificity in Romance Languaje, Université Konstanz, Konstanz.

Li , Ch. \& Thompson, S. (1976). Subjects and topic:A new tipology of language. En Ch. Li (Ed.), Subject and Topic (pp. 457-489). New York:Academic Press.

Marcos Marín, F. (I992). Corpus oral de referencia del español contemporáneo. Madrid:Universidad Autónoma de Madrid.

Padilla, X. (2005). Pragmática del orden de palabras. Alicante: Publicaciones Universidad Alicante.

Pensado, C. (1995a). La creación del complemento directo preposicional y la flexión de los pronombres personales en las lenguas románicas. En C. Pensado (Ed.), El complemento directo preposicional (pp. 179-233). Madrid:Visor Libros.

Pensado, C. (1995b). El complemento directo preposicional: Estado de la cuestión y bibliografía comentada. En C. Pensado (Ed.), El complemento directo preposicional (pp. I I-59). Madrid: Visor Libros.

Pérez, G. (1998). Uso de las dislocaciones a la derecha y a la izquierda en castellano e italiano. Interlingüística, 98, 253-260.

Prince, E. (198I). Toward a taxonomy of given-new information. En P. Cole (Ed.), Radical pragmatics (pp. 223-255). New York:Academic Press. 
Real Academia Española (2009). Nueva gramática de la lengua española. Madrid: Espasa Libros.

Rodríguez, T. M. (2005). Manual de sintaxis del español. Madrid: Castalia.

Sanz, B. (200I). El habla universitaria de la ciudad de México. Tesis de licenciatura. México:UNAM. van Dijk, T. (1986). Texto y contexto (semántica y pragmática del discurso). Madrid: Cátedra.

\section{NOTAS}

I Para este corpus -publicación conjunta del Centro de Lingüística Hispánica de la UNAM y el Centro de Estudios Lingüísticos y Literarios del Colegio de México- se transcribieron 47 muestras de las encuestas realizadas en el trabajo de campo encaminado a levantar el Atlas Lingüístico de México. En él existen muestras de cada uno de los estados de la República Mexicana y se compone de conversaciones informales entre los informantes y los encuestadores.

Es importante hacer notar que, a fin de analizar una cantidad de datos similar a la de los otros tres corpora, tan solo se obtuvieron fichas de 197,740 palabras de un total de 226,966 , o dicho de otro modo, se analizaron 4I encuestas de un total de 47.

2 Corpus conformado a partir de las transcripciones de las grabaciones magnetofónicas que los investigadores del Centro de Lingüística Hispánica de la UNAM recopilaron sobre el habla popular del español de la ciudad de México como parte del proyecto del 'Programa Interamericano de Lingüística y Enseñanza de Idiomas'. Dicho corpus consta de 166,934 palabras y se conforma de 34 encuestas, para lo cual se eligieron informantes de ambos sexos, de tres generaciones sucesivas: la primera de jóvenes entre 18 y 34 años; la segunda de personas situadas entre 35 y 45 años; $y$ la tercera de hablantes de 50 años en adelante. En el corpus se manejan tres tipos diferentes de encuesta:a) diálogo entre un informante y el investigador; b) diálogo entre dos informantes; $y$ c) grabaciones secretas.

3 Las muestras se circunscriben al habla culta media (habitual) con referencias a las actitudes formales (habla esmerada) e informales (habla familiar).
El corpus está conformado por cuatro tipos de grabaciones: a) grabación secreta de un diálogo espontáneo; b) diálogo libre entre dos informantes; c) entrevista; d) elocuciones en actitudes formales (conferencias, clases, discursos, etcétera). El H.C.M. se realizó a partir de las transcripciones de las grabaciones magnetofónicas que los investigadores del Centro de Lingüística Hispánica de la UNAM realizaron para el 'Proyecto de estudio coordinado de la norma lingüística culta de las principales ciudades de lberoamérica y la Península Ibérica'. Los informantes de este corpus son hombres y mujeres, en una distribución del $50 \%$ aproximadamente. Se eligieron representantes de tres generaciones, de acuerdo con la siguiente distribución: a) de 25 a 35 años $=30 \%$; b) de 36 a 55 años $=45 \%$; c) de más de 55 años $=25 \%$. Por último, el corpus se compone de 32 encuestas que dan un total de 170,940 palabras.

4 Este corpus se realizó en el año 2000 con el propósito de obtener los datos necesarios para una investigación sociolingüística.Ver Sanz Martin (200I). El corpus se compone de 32 encuestas que suman 137,860 palabras. En el se manejan dos tipos de encuestas: a) grabación secreta de un diálogo espontáneo y b) entrevista. El procedemiento para elaborar el corpus consistió en la trascripción de grabaciones de informantes universitarios, hombres y mujeres, en una distribución del $50 \%$. A fin de determinar si se registraban diferencias relacionadas con tiempo de estancia en la universidad, se seleccionaron representantes de los dos primeros y los dos últimos años de la carrera.

Los informantes se eligieron atendiendo a las siguientes características:

Edad: Los hablantes de los primeros años de la 
carrera debían tener entre 18 y 20 años y de los últimos, entre 22 y 24.

Escolaridad: Los informantes eran estudiantes de universidades públicas y privadas de la ciudad de México. El $50 \%$ de estos pertenecía a la Universidad Nacional Autónoma de México (UNAM) y el resto a universidades particulares: Universidad Iberoamericana (UIA), Universidad Intercontinental (UIC), Universidad La Salle, Universidad Latinoamericana (ULA), Universidad Panamericana (UP) y Universidad del Valle de México (UVM).

Con el fin de determinar de manera más homogénea las posibles diferencias entre universidades públicas y privadas se eligieron informantes que pertenecieran a carreras de humanidades o ciencias sociales. Todos los informantes nacieron en la ciudad de México o residían en ella desde los cinco años de edad como mínimo y son hijos de hispanohablantes.

5 Oraciones como 'María tiene novio' o 'Juan tiene un hijo'.

6 En la bibliografía sobre la estructura informativa de la oración, también se suelen emplear los términos 'tema' y 'rema'. De acuerdo con Padilla (2005: 52), "el tema es el punto de partida inicial, porque de él se van a decir cosas nuevas (el rema); y el tópico, por definición, es una noción inicial de la que también se dirá algo, el comentario. Lo que tienen, pues, en común el tema y el tópico es 'ser el punto de partida'. Sin embargo, a pesar de esta coincidencia, la enunciación y el contexto son dos ejes de coordenadas distintos (dos planos) y, en nuestra opinión, es necesario considerar dos estructuras diferentes."
7 Cabe señalar que la topicalización y la voz pasiva compiten en el discurso para darle el estatus de tópico a un elemento. Sin embargo, la topicalización no implica un cambio en la transitividad de la oración, a diferencia de la voz pasiva.

8 No obstante, estos ejemplos podrían aparecer en la poesía a manera de hipérbaton.

9 Su presencia o ausencia se ve determinada por factores tales como el grado de animación e individuación del objeto y los rasgos semánticos del verbo, entre otros.

I0 Las mayúsculas indican el foco.

II El término nominativo pendens es un término acuñado para el latín que se define como aquel que, por una suerte de anacoluto, queda al comienzo de la frase, como un sujeto efectivo del que se va a tratar, si bien interrumpidas sus relaciones gramaticales. Por similitud con el latín se designan también como nominativos pendientes en español usos como 'tú, como te agarre, te mato'.

I 2 Se excluyen los cuatro ejemplos de topicalización de esta Tabla, pues como habrá de recordar el lector, estos siempre aparecen marcados, lo cual no nos permite hacer un análisis contrastivo.

13 Estos datos corresponden a los cuatro corpora. En el habla popular se observa que los porcentajes disminuyen mucho más dramáticamente. Así, por ejemplo, en el H.P.C.M., los ODs [+hum] no referenciales o genéricos marcados tan solo constituyen el $33,33 \%$. 